\title{
Religious versus Conventional Psychotherapy for Major Depression in Patients with Chronic Medical Illness: Rationale, Methods, and Preliminary Results
}

\author{
Harold G. Koenig1,2 \\ ${ }^{1}$ Departments of Psychiatry and Medicine, Duke University Medical Center, Box 3400 Medical Center, Durham, NC 27705, USA \\ ${ }^{2}$ Department of Medicine, King Abdulaziz University, Jeddah 21413, Saudi Arabia
}

Correspondence should be addressed to Harold G. Koenig, Harold.Koenig@dm.duke.edu

Received 2 January 2012; Accepted 6 March 2012

Academic Editor: Rachel E. Dew

Copyright (C) 2012 Harold G. Koenig. This is an open access article distributed under the Creative Commons Attribution License, which permits unrestricted use, distribution, and reproduction in any medium, provided the original work is properly cited.

\begin{abstract}
This paper (1) reviews the physical and religious barriers to CBT that disabled medically ill-depressed patients face, (2) discusses research on the relationship between religion and depression-induced physiological changes, (3) describes an ongoing randomized clinical trial of religious versus secular CBT in chronically ill patients with mild-to-moderate major depression designed to (a) overcome physical and religious barriers to CBT and (b) compare the efficacy of religious versus secular CBT in relieving depression and improving immune and endocrine functions, and (4) presents preliminary results that illustrate the technical difficulties that have been encountered in implementing this trial. CBT is being delivered remotely via instant messaging, telephone, or Skype, and Christian, Jewish, Muslim, Buddhist, and Hindu versions of religious CBT are being developed. The preliminary results described here are particular to the technologies employed in this study and are not results from the CBT clinical trial whose findings will be published in the future after the study ends and data are analyzed. The ultimate goal is to determine if a psychotherapy delivered remotely that integrates patients' religious resources improves depression more quickly than a therapy that ignores them, and whether religious CBT is more effective than conventional CBT in reversing depression-induced physiological changes.
\end{abstract}

\section{Introduction}

Depression is a major public health problem. Based on a joint study conducted by the Harvard School of Public Health and the World Health Organization, depression was the leading cause of disability in the world (measured by years of life lived with disability) in 1990 [1] and, in 2020, is expected to be the world's second leading cause of disability, surpassed only by cardiovascular disease [2]. The lifetime prevalence of depression in the USA is $20 \%$ in women and $10 \%$ in men [3].

Depression is widespread in patients with chronic disabling medical illness. While the point prevalence of major depression among the general population in the United States is $7 \%$ [4], this figure increases to $10 \%$ to $45 \%$ among patients with medical illness depending on setting [5-8]. Not surprising, the use of antidepressants by primary care physicians has increased dramatically in recent years [9]. Treating with antidepressants, while lifesaving for many, comes with it the risk of side effects in medically frail patients and increases the risk of drug interactions with medications prescribed for nonpsychiatric illness [10]. This is especially true since major depression is already a potent risk factor for disease morbidity, with depressed medical patients having double the mortality of those without depression [11, 12]. Furthermore, medications are expensive, and managing side effects or drug interactions increases the cost further.

Psychotherapy has also been shown to benefit depressed medical patients. The kinds of depression seen in primary care medicine are often situation-specific and due to life changes brought on by physical illness, including day-today problems with functioning at home and work. Thus, psychotherapeutic approaches focused on helping patients adjust to difficult real life circumstances are useful in depressed patients seen in primary care settings. Not surprising, psychological approaches such as cognitive-behavioral therapy (CBT) have been particularly effective in treating 
depression in medical patients, often done by addressing the maladaptive beliefs and thoughts related to medical illness that initiate and maintain depression [13-16].

The aims of this paper are to (1) review the physical and religious barriers to psychotherapy that disabled medically ill-depressed patients face, (2) discuss research on the relationship between religious involvement and depression, and their relationships to physiological changes influencing the course of medical illness, (3) describe an ongoing randomized clinical trial designed to overcome physical and religious barriers to psychotherapy in the medically ill by utilizing remote delivery methods for CBT that integrate religious resources into psychotherapy, and (4) present preliminary results that illustrate the technical difficulties that we have encountered in implementing this trial.

\section{Barriers to Psychotherapy}

While psychological treatments for depression are known to be effective, there are numerous barriers to referral, compliance, and follow-up of persons with depressive disorders. These include physical, cultural, and religious barriers. Physical barriers to psychotherapy for medically ill-disabled patients are formidable. Medical patients with mobility problems or those who are home bound may have trouble accessing psychotherapy (i.e., traveling to therapists' offices, sitting in waiting rooms, etc.). To address this barrier, online and telephone approaches to delivering CBT have been developed, and are effective in and acceptable to medical patients with depression $[17,18]$.

2.1. Online Communications. Online communications are now widespread in the United States and around the world. Of 6.8 billion people, $25 \%$ (1.7 billion) use the Internet [19]. Of the 341 million people in North America, nearly 75\% (252 million) use the Internet. In 2005, close to 75 million Americans used e-mail and search engines on an average day (including $29 \%$ of those over age 50 ) [20,21]. That number has increased considerably since then, not to mention the millions who now have a MySpace or Facebook account (74\% of all Americans ages 18 to 34, and $25 \%$ of those ages 55 or older), or the estimated 15 million who use Twitter [22]. One of the fastest growing groups of Internet users is older adults; $77 \%$ of all persons over age 55 use the Internet to search for healthcare information [23].

2.2. Online $C B T$. Individual cognitive-behavior therapy (CBT) can be offered online by a therapist using instant messaging, during which client and therapist communicate in real time with typewritten responses. Benefits of this approach include flexibility and optimal use of patient and therapist time, outreach to patients for whom travel to treatment centers is difficult for reasons of geography or disability, and access to foreign language therapists. Furthermore, this approach is acceptable to depressed patients, and therapy without face-to-face contact may encourage greater disclosure [24].

The Lancet published the first report of a randomized controlled trial (RCT) of therapist-delivered online CBT for moderately severe depression in primary care patients in 2009 [25]. The study found that CBT by this method was significantly more beneficial than usual care provided by primary care physicians. Those benefits were maintained over at least 8 months. This means that a relatively small number of therapists can cover a wide geographical area and be available to patients at a range of times. The way that patients express their feelings may also impact treatment effectiveness. Online CBT takes advantage of the fact that writing about traumatic experiences improves outcomes [26, 27]. This appears especially true when writing about events from a religious viewpoint $[28,29]$.

2.3. Telephone CBT. An issue with online CBT, particularly when delivered alone on the Internet without therapist guidance, has been "dropouts" during treatment [30]. Even with therapist-delivered online CBT, this remains a problem (dropout rate was $28 \%$ in the Lancet study). To minimize dropouts and boost effects, it has been recommended that a telephone component be added [31] since telephone therapy is known to increase compliance [32]. Furthermore, structured CBT delivered by telephone has been shown to be both clinically effective and cost effective in treating medical patients with depression [33].

\section{Religion and Depression}

Besides physical barriers that depressed disabled medically ill patients encounter when seeking psychotherapy, there are also religious barriers. When religious patients become depressed, their beliefs may interfere with their acceptance of and compliance with conventional treatments, especially psychotherapy. Many such patients shy away from secular psychotherapy because they perceive it as unsympathetic to their religious beliefs [34]. Religious patients may also feel that seeking therapy means abandoning their faith in favor of secular treatments. Finally, religious persons may feel guilty or ashamed about being depressed and thus fail to address it with their clergy and avoid seeking support within their faith community.

Clergy have traditionally served as front-line mental health providers in communities across the USA, providing nearly as many hours of counseling as does the entire membership of the American Psychological Association [35]. Consider that clergy spend on average $15 \%$ of their time in counseling activities, providing over 140 million hours of mental health services each year, not including the activities of nearly 100,000 full-time nuns or chaplains. Furthermore, they do not charge for their services, and there is no stigma associated with this type of counseling. Thus, depressed religious persons often receive their first treatment by clergy or other counselors within their faith community.

Treatment within the faith community, however, is not always effective, especially for more severe depression, requiring referral to mental health professionals for additional treatment. The problem is that the relationship between clergy and mental health professionals has not always been good. In fact, there is a long history of conflict between religious and mental health professionals, beginning with 
Freud's description of religion as "the universal obsessional neurosis." [36] There is often open resistance to consideration of religious beliefs in conventional mental health care, resistance that is clear from a recent discussion among British psychiatrists (see e-letters in response to two recent articles in The Psychiatrist) [37, 38]. Negative attitudes toward religion by mental health professionals are not limited to Great Britain. A systematic review of the religious content of DSM-III-R found that nearly one-quarter of all cases of mental illness included religious descriptions [39]. More recent publications by mental health professionals continue to emphasize a lack of concern for patients' religious beliefs, $[40,41]$ and a recent national survey of USA psychiatrists found that $56 \%$ never, rarely, or only sometimes inquire about religious/spiritual issues in patients with depression or anxiety [42].

Based on this generally neglectful (and at times disparaging) view held by some mental health professionals toward religion, religious professionals are often reluctant to refer members of their congregation to mental health professionals, especially for psychotherapy that seeks to alter beliefs and attitudes. Failure of clergy to refer may prevent many patients from receiving the treatment they need. Furthermore, if patients are members of a faith community and that community does not reinforce (or perhaps even counteracts) the gains made in psychotherapy, then those gains may not last.

\section{Depression, Religion, and Physiological Changes}

Whether religion is a resource (as clergy claim) or a liability (as mental health specialists like Freud claim) to depressed medical patients needs to be established before bringing down the barrier that stands between mental health care and religion. Like it or not, religious involvement is important to the vast majority people in the USA and around the world [43]. According to a January 2009 Gallup Poll, 65\% of Americans indicated that religion is an important part of their daily life, a figure that increases to over $75 \%$ in the southeastern USA [44]. Likewise, according to the Pew Foundation's national survey of 35,000 Americans, 56\% indicated that religion was "very important" in their lives, a figure that increases to $69 \%$ in the southeastern USA This is especially true for medical patients, who often turn to religious beliefs to cope with illness [45].

Literally hundreds of qualitative and quantitative studies document high rates of religious coping behaviors in those trying to cope with medical illness [46, 47]. In some areas of the USA, nearly $90 \%$ of hospitalized patients with medical problems use religion to cope, and of those who do, nearly half (45\%) report that religion is the most important factor that keeps them going [48]. Furthermore, greater religiosity predicts a faster resolution of depressive symptoms in medical patients over time, increasing the speed of remission by 50 to 70 percent overall, but especially in those with persistent physical disability, in whom it predicts a more than 100 percent increase in speed of remission [49-52].
Religious involvement has also been associated with positive emotions such as optimism and purpose in life [53], as well as gratefulness, generosity, and altruism [54-56]. These characteristics may enhance well-being and counteract maladaptive cognitions and behaviors that maintain depression [57]. Religious people, however, are not exempt from depression, especially when serious health problems strike. In a study at Duke Hospital, $64 \%$ of medical inpatients over age 50 with major depression (diagnosed using the Structured Clinical Interview for Depression (SCID)) indicated they were both spiritual and religious and $76 \%$ prayed at least once daily [58].

\section{Consideration of Religious Beliefs in Therapy}

Depression not only destroys quality of life but may also affect the physical body by interfering with immune and endocrine functioning. Religious beliefs and behaviors that facilitate coping with life stress may help to normalize those changes.

5.1. Physiological Effects of Depression. There is evidence that the alterations in immune and endocrine function associated with depression increase medical morbidity by increasing the risk of infection [59], inflammatory disorders [60], and possibly malignancy [61-63]. This relationship, however, is a complex one that is likely bidirectional in nature [64]. Furthermore, depression is known to stimulate some components of the immune system and suppress others. Stimulation of proinflammatory cytokines can lead to sickness behaviors that resemble depression, which has led to consideration of how immune and endocrine functions influence the pathophysiology of depression, especially when depression develops in a setting of chronic stress [65].

Regardless of direction of effect, major depression is associated with a host of immune [66], endocrine [67], and proinflammatory functions [68] that could adversely affect physical health and response to medical treatments. Depression is associated with an altered balance in the Th1/Th2 ratio, that is, higher pro-inflammatory Th1 cytokines (IL-1, IL-12, INF- $\gamma$ ), higher pro-inflammatory monocytic cytokines (IL-6, TNF- $\alpha$ ) [69-71], and lower antiinflammatory Th2 cytokines (IL-4, IL-10) [72]. Depressed patients also have reduced natural killer (NK) cell cytotoxicity [73-75] and diminished lymphocyte responses to phytohemagglutinin and concanavalin A $[76,77]$.

Impaired immune functions associated with depression also appear to normalize in response to treatment with electroconvulsive therapy (serum TNF $\alpha$ ) [78], antidepressant drug therapy (serum TNF $\alpha$ and CRP) [79], and psychological interventions [80] (due in part to a return of the pro-/anti-inflammatory cytokine balance). A number of randomized clinical trials involving psychological interventions that relieve depression or boost positive emotions have reported improvement in immune and/or endocrine functions. For example, Antoni et al. conducted a 10-week CBT stress-management program in human-immunodeficiency-virus- (HIV-) infected men [81]. The intervention significantly increased naïve CD4+ T cells in blood over 
a 12-month follow-up among those in the CBT group ( $n=$ 16) compared to controls $(n=9)$. This effect was mediated by a reduction in depressive symptoms and a decrease in urinary cortisol levels. A more recent study by Antoni et al. examined the effects of a 10-week cognitive behavioral stress management program in 128 women with breast cancer, finding that the intervention significantly lowered serum cortisol, increased $\mathrm{Th}_{1}$ pro-inflammatory cytokines (IL-2 and INF- $\gamma$ ), and increased IL-2: IL-4 ratio [82].

In another clinical trial, Van Middendorp et al. conducted an emotional disclosure intervention (4 weekly sessions) in 68 nondepressed patients with rheumatoid arthritis, finding a reduction in urinary cortisol, a reduction of serum INF- $\gamma$, and a trend towards a reduction in IL-6 $(P=0.07)$ [83]. Also, a recent intervention by Lee Berk et al. to increase positive emotions (via mirthful laughter) in 20 high-risk diabetics with hypertension and hyperlipidemia found that the intervention lowered serum epinephrine, norepinephrine, INF- $\gamma$, CRP, TNF- $\alpha$, and IL-6 [84]. Finally, Roberts et al. found that the hypocortisolism in 41 subjects with chronic fatigue syndrome (a depression-like syndrome) was improved following 15 sessions with CBT [85]; thus, whether cortisol is pathologically high or low, psychological therapies may help normalize levels.

In summary, psychotherapeutic treatments that increase positive emotions (particularly CBT) appear to increase naïve CD4+ cells, increase $\mathrm{NK}$ cell cytotoxicity, reduce IL-6, reduce TNF- $\alpha$, reduce CRP, reduce INF- $\gamma$ (sometimes increasing in nondepressed female patients), decrease catecholamines, and normalize (decreasing or increasing) cortisol.

5.2. Physiological Effects of Religion. As noted previously, religious involvement has been associated with better mental health. However, it is also associated with better physical health and greater longevity $[86,87]$. The mechanisms that explain the association with physical health are unclear but likely involve behavioral and psychosocial factors operating at least partly through immune/endocrine pathways related to stress [88-90]. There is some evidence that religious involvement is associated with better immune and endocrine functions, although no studies have yet examined the effects of a religious psychotherapy on these functions.

For example, Sephton et al. examined the relationship between religious involvement and immune function in 112 women with metastatic breast cancer [91]. Religious expression was positively related to the total number of circulating T cells $(r=0.24, P=0.01)$ and helper T cells ( $r=0.23, P=0.01)$, and controlling for social network size, disease, and medical treatment variables had little effect on these relationships. Investigators also found positive associations between religious expression and cytotoxic $\mathrm{T}$ cells $(r=0.18, P<0.05)$ and a trend towards greater $\mathrm{NK}$ cell numbers $(r=0.14, P=0.07)$.

Studying a vulnerable population, Ironson et al. examined the effects of changes in spirituality/religiousness (S/R) following the diagnosis of HIV on CD4 counts ( $\mathrm{T}$ cells) and viral load during 4 years of follow-up [92]. Hierarchical linear modeling was used to examine the effects of changes in $\mathrm{S} / \mathrm{R}$ over time with the outcome being slopes of change in CD4 cells and viral load during follow-up. Patients who reported an increase in S/R after diagnosis experienced significantly less decrease in CD4 counts and less increase in viral load during the 4-year follow-up. Results were independent of church attendance and initial disease status, medication use, age, gender, race, education, health behaviors, depression, hopelessness, optimism coping, and social support. In fact, among all significant predictors of CD4 cell count and viral load, change in S/R was the most powerful predictor. A number of other studies have found similar connections between religious involvement and other immune functions ( $\mathrm{T}$ cells, in particular) [93-95], pro-inflammatory indicators (IL-6) [96-98], and endocrine measures (specifically cortisol) [99-103].

In contrast to the numerous observational studies cited perviously, there have been far fewer intervention studies. One that examined nondepressed HIV+ patients reported that a stress management intervention designed to increase spiritual growth led to an increase in lymphocyte proliferation and a 3-fold increase of INF- $\gamma$ [104]. Likewise, Eastern spiritual meditation has been shown to increase antibody response to influenza vaccine [105], alter the ratio of pro-/anti-inflammatory cytokines [106, 107], increase NK cell activity [107], reduce cortisol [107-110], and decrease catecholamine $[111,112]$ levels (and in one study, there was a trend toward superiority over conventional CBT [113]).

Thus, psychotherapy for depression that utilizes patients' religious resources in therapy may help to normalize endocrine and immune dysfunctions, perhaps even more so than conventional treatments [114]. Whether or not this is true, however, is completely unknown. The study described below is the first randomized clinical trial to address this gap in the literature and to examine whether religious CBT is equally effective, more effective, or less effective than conventional CBT in depressed patients with chronic medical illness. The effectiveness of religious CBT is suggested both (1) by an earlier study showing that religious CBT was more effective than conventional CBT in religious patients [115] and (2) by a study showing that patients receiving conventional CBT responded more quickly to the therapy if they indicated that religion was important to them [116].

\section{Ongoing Randomized Clinical Trial}

Psychotherapy that takes into account patients' religious beliefs as potential resources in therapy may not only help to overcome religious barriers to therapy but may also be more effective in resolving depressive symptoms and reversing depression-induced physiological changes. The efficacy of religious psychotherapy, that is, taking into account the religious beliefs and practices of patients and utilizing them in therapy, however, has yet to be examined in medical settings. Religious CBT has been shown to increase the speed of remission in depressed healthy religious patients and do so beyond that achieved by conventional CBT [117-119]. Likewise, a number of studies that utilized patients' religious beliefs in therapy have reported results superior to secular 
treatments or usual care, especially in religious patients [120124].

Finally, there is plenty of evidence that many patients in the United States prefer to have their religious beliefs integrated into therapy. For example, one recent study found that $77 \%$ to $83 \%$ of adults aged 55 or older with depression and comorbid chronic medical illness wished to include religion in their therapy [125]. Likewise, in a survey of a more general population of 74 individuals receiving counseling, Rose et al. found that only $18 \%$ of patients said they did not want to discuss religion or spirituality in psychotherapy and only $8 \%$ said they wanted to discuss spiritual but not religious issues [126]. Likewise, Kelly found in a national survey that only $19 \%$ of respondents did not want to integrate religious/spiritual beliefs and values into therapy [127]. Thus, from the patient's perspective, there appears to be little resistance to utilizing their religious beliefs in therapy.

Benefits resulting from addressing religious beliefs in therapy may stem partly from redirecting attention away from a focus on loss and preoccupation with self and instead centering one's thoughts on positive processes such as gratitude, altruism, and generosity. Such positive cognitions have been shown to predict lower depressive symptoms [128-131]. Furthermore, religious cognitions that promote purpose and meaning in life and a hopeful and optimistic attitude toward circumstances may help to counter the negative cognitions and behaviors associated with depression. Indeed, dozens of studies have reported a link between positive emotions such as optimism and purpose in life, religious involvement, and fewer depressive symptoms [132]. Having a common worldview and explanatory model that gives meaning and purpose to negative life events may also strengthen the therapeutic alliance between patient and therapist, which could contribute to treatment efficacy [133]. This may be particularly true for minority populations who often suffer from disparities in psychiatric care and yet tend to be very religious.

\section{The Interventions}

We are now in the first phase of a randomized clinical trail being conducted at two sites, Duke University Health Systems in the Triangle region of North Carolina and Glendale Adventist Medical Center in Los Angeles County. During Phase I (Rounsaville 1a) [134], we are developing and further refining a manual to guide the delivery of religious CBT and are conducting an open trial to assess subject recruitment and to allow therapists to gain experience with the treatment and method of delivery. In this preliminary phase, religious and conventional CBT are being delivered online by instant messaging, over the telephone, or by Skype to determine which method of delivery is most acceptable, preferred, and likely to be complied with by patients during the randomized clinical trial in Phase II.

In Phase II (Rounsaville 1b), we will conduct a randomized proof of concept comparison of conventional CBT versus religious CBT that will (1) further demonstrate feasibility of recruitment and subject compliance, (2) confirm the expected clinically meaningful difference (effect size) in the therapies, and (3) show differential effects in reversing depression-induced immune and endocrine functions. In this head-to-head trial, 70 persons who are at least somewhat religious/spiritual and ages 18-85 with an episode of major depression (diagnosed by the Mini International Neuropsychiatric Inventory using DSM-IV criteria), moderate severity of depression based on Beck Depression Inventory (BDI) scores, and at least one chronic medical illness will be randomized to either conventional CBT or religious CBT. Excluded will be patients with significant cognitive impairment, those currently receiving psychotherapy, those that meet criteria on the MINI for psychotic disorder, alcohol or substance abuse, or PTSD, those with a history of bipolar disorder, active suicidal thoughts (passive suicidal thoughts will not exclude), diagnosis of HIV/AIDS, autoimmune diseases, or endocrine disorders likely to affect stress hormone levels, or taking immunosuppressant drugs (due to proposed immune and endocrine analyses).

The trial will consist of ten 50 min sessions, administered by licensed master's level therapists and delivered over 12 weeks. The primary endpoint will be depressive symptoms on the BDI (clinician-rated scales like the Hamilton or MADRS are not being used because nonclinicians blind to study group will be administering outcome assessments). Subjects will be assessed on the BDI at baseline, 4 weeks, 8 weeks, 12 weeks, and 24 weeks. Immune (pro-inflammatory and anti-inflammatory cytokines) and endocrine (urinary cortisol, epinephrine, and norepinephrine) measures will be assessed at baseline, immediately at the end of therapy (12 weeks), and at 24 weeks from baseline.

\section{Preliminary Results}

Both interventions are taking a CBT approach documented in treatment manuals. Depressed persons with chronic medical illness have often allowed their health problems and disability (i.e., circumstances) to shape the way they think and view their world. Depression is often maintained by a negative worldview that sees the person's situation as hopeless and without meaning or purpose. Both conventional and religious CBT seek to alter these dysfunctional, maladaptive beliefs, replacing them with positive, realistic beliefs and behaviors that generate positive emotions.

8.1. Conventional CBT. CCBT helps depressed patients understand the links between thoughts, emotions, and behavior. It uses guided discovery, Socratic questioning, and challenge of automatic negative thoughts to help patients identify and appraise their cognitions and determine problematic behaviors. Interventions include activity scheduling, along with practice assignments, in which clients test out ideas and behaviors discussed during sessions. In this arm, therapists will be asked to avoid reference to the participant's faith or religious belief. If religious issues come up, therapists will gently redirect the patient to more secular ways of approaching the issue and, if necessary, will address religious issues in the broadest conventional way possible, relating them to other cognitions/behaviors usually addressed in 
conventional CBT. We felt justified in doing this because most CBT today does not utilize and integrate the religious beliefs of patients into psychotherapy.

8.2. Religious CBT. Religious CBT follows the same process described for CCBT, except that religious beliefs and motivations will be utilized to stimulate changes in thought and behavior. For example, participants may have obsessive guilt about sin or punishment, report religious doubt, or want to discuss the cognitive and emotional elements of their faith. In RCBT all those issues will be considered fully acceptable as part of therapy, including an emphasis on religious resources. In other words, RCBT uses religious rationales (based on the subject's faith tradition) and religious arguments to counter irrational thoughts and utilizes religious behaviors (involvement in the religious community) to increase supportive relationships. RCBT teaches patients to use their own religious teachings, doctrines, and behaviors to help change maladaptive beliefs, values, and behaviors so as to transform their worldview into one that is meaningful, hopeful, and optimistic, one that is incompatible with depression. RCBT seeks to bolster powerful religious beliefs that promote behaviors such as forgiveness, gratitude, generosity, and altruism (focusing on others and on God) that generate meaning and purpose, optimism, and hope, which neutralize depression.

The RCBT manual is initially being developed within a Christian framework and will then be adapted to the subject's faith tradition (i.e., versions of the manual for Jewish, Hindu, Buddhist, and Muslim patients). These versions of the manual will be prepared by experienced psychotherapists well versed each of these faith traditions, who will work under the direction of Ken Pargament, a psychotherapist widely renowned for his writings on integrating spirituality into psychotherapy [135]. The therapists who develop the different religious versions will help supervise study therapists while they are treating patients in these faith traditions.

\section{Conclusions}

Preliminary results from Phase I indicate that of the first 82 patients screened for inclusion (from North Carolina and Los Angeles County), $78 \%$ had a computer at home, $77 \%$ had access to the Internet at home, $75 \%$ could type easily and quickly on the computer, $68 \%$ had a landline telephone, $95 \%$ had a cell phone, but only $30 \%$ had Skype (or equivalent program) and a webcam. Most ( $>80 \%)$ preferred therapy by telephone, $9 \%$ preferred online therapy, and $9 \%$ preferred therapy via Skype. Patients were also asked what method of therapy they were not willing to try; $70 \%$ said they were unwilling to try online therapy and $78 \%$ were unwilling to try Skype.

Of the 82 subjects, 18 met inclusion criteria and were randomized to treatment arm (one to online, two to Skype, and 15 to telephone, based on what subjects were willing to do). Technical issues encountered during therapy have been the biggest problem. The telephone route has had the fewest issues; $84 \%$ of telephone sessions (delivered by twoperson conference call) had no technical difficulties; $8 \%$ had a problem with conference call ending or dropping; 5\% had difficulty with sound; and one patient's cell phone battery died. Overall, only $0.6 \%$ of telephone therapy session time was wasted dealing with technical issues (during the course of 57 therapy sessions). For the single subject who was willing to try the online method thus far, difficulty connecting to the online platform (PsychologyOnline) was a problem for all sessions; overall, $35 \%$ of session therapy time was wasted on dealing with this issue. With regard to Skype, only 30\% of 20 sessions proceeded without technical difficulties; $30 \%$ had difficulty with sound, $25 \%$ had difficulty connecting with Skype over the computer; and 5\% had trouble with delay in picture, video call dropped, or session could not be recorded. Overall, 7\% of therapy session time for Skype was spent dealing with technical issues. These preliminary findings suggest that the most preferred method of delivering the therapy and the one with the least technical difficulties is therapy by telephone, although we need more experience with the online and Skype methods.

\section{Conclusions}

Major depression is a common psychiatric illness, especially prevalent among persons with chronic medical illness, that can adversely affect physical health and medical outcomes by altering immune and endocrine functions. Religion is widespread and often used to cope with medical illness and problems with physical functioning. In this study, we are testing whether a psychological therapy that takes advantage of patients' religious resources improves depression more or less quickly than conventional therapy and reverses the adverse physiological changes associated with depression.

The results from this study will be important because they are relevant to therapists other than those who explicitly practice pastoral counseling, extending to secular therapists as well. If $65 \%$ of Americans indicate that religion is an important part of daily life and $80 \%$ of depressed patients wish to include it in therapy, then all therapists (whether they have explicit training in pastoral counseling or not) are likely to encounter patients among their clientele who will prefer this approach. Interestingly, Propst et al. in their study of religious versus conventional CBT found that delivery of religious CBT by secular therapists was at least as effective (if not more so) than religious CBT delivered by religious therapists [136].

In their 2009 review of religion in psychotherapy, Post and Wade make two points relevant to this issue [137]. First, although therapists in general are less overtly religious than patients, many therapists have spiritual beliefs that should assist them in appreciating the role that patients' religious beliefs play as a resource in their mental health. Second, while it is helpful for therapists to be well versed in the basic tenets of their patients' religious beliefs, it is not necessary for them to be experts in religion: "instead, approaching religious/spiritual clients with an openness and willingness to engage the religious/spiritual conversation will help clients to feel comfortable expressing their needs." These authors concluded that religious interventions in psychotherapy can 
be effectively delivered by therapists with a wide range of religious/spiritual beliefs, not only pastoral counselors.

\section{Conflict of Interests}

The author have no conflict of interests.

\section{Acknowledgments}

This work was funded by the John Templeton Foundation. This paper is supported by a grant from the John Templeton Foundation and by support from the Center for Spirituality, Theology and Health.

\section{References}

[1] A. D. Lopez and C. C. J. L. Murray, "The global burden of disease, 1990-2020," Nature Medicine, vol. 4, no. 11, pp. 12411243, 1998.

[2] C. Murray and A. Lopez, The Global Burden of Disease, Harvard University Press, Cambridge, Mass, USA, 1996.

[3] D. C. Steffens, I. Skoog, M. C. Norton et al., "Prevalence of depression and its treatment in an elderly population: the Cache County study," Archives of General Psychiatry, vol. 57, no. 6, pp. 601-607, 2000.

[4] R. C. Kessler, P. Berglund, O. Demler et al., "The epidemiology of major depressive disorder: results from the National Comorbidity Survey Replication (NCS-R)," JAMA, vol. 289, no. 23, pp. 3095-3105, 2003.

[5] M. A. Kitchell, R. F. Barnes, and R. C. Veith, "Screening for depression in hospitalized geriatric medical patients," Journal of the American Geriatrics Society, vol. 30, no. 3, pp. 174-177, 1982.

[6] H. G. Koenig, K. G. Meador, H. J. Cohen, and D. G. Blazer, "Depression in elderly hospitalized patients with medical illness," Archives of Internal Medicine, vol. 148, no. 9, pp. 1929-1936, 1988.

[7] H. G. Koenig, L. K. George, B. L. Peterson, and C. F. Pieper, "Depression in medically ill hospitalized older adults: prevalence, characteristics, and course of symptoms according to six diagnostic schemes," American Journal of Psychiatry, vol. 154, no. 10, pp. 1376-1383, 1997.

[8] T. Rosemann, M. Backenstrass, K. Joest, A. Rosemann, J. Szecsenyi, and G. Laux, "Predictors of depression in a sample of 1,021 primary care patients with osteoarthritis," Arthritis Care and Research, vol. 57, no. 3, pp. 415-422, 2007.

[9] M. Olfson and S. C. Marcus, "National patterns in antidepressant medication treatment," Archives of General Psychiatry, vol. 66, no. 8, pp. 848-856, 2009.

[10] E. Spina, V. Santoro, and C. D’Arrigo, "Clinically relevant pharmacokinetic drug interactions with second-generation antidepressants: an update," Clinical Therapeutics, vol. 30, no. 7, pp. 1206-1227, 2008.

[11] L. R. Wulsin, G. E. Vaillant, and V. E. Wells, "A systematic review of the mortality of depression," Psychosomatic Medicine, vol. 61, no. 1, pp. 6-17, 1999.

[12] H. G. Koenig, F. Shelp, V. Goli, H. J. Cohen, and D. G. Blazer, "Survival and health care utilization in elderly medical inpatients with major depression," Journal of the American Geriatrics Society, vol. 37, no. 7, pp. 599-606, 1989.

[13] E. Ward, M. King, M. Lloyd et al., "Randomised controlled trial of non-directive counselling, cognitive-behaviour therapy, and usual general practitioner care for patients with depression. I: clinical effectiveness," British Medical Journal, vol. 321, no. 7273, pp. 1383-1388, 2000.

[14] P. Bower, S. Byford, B. Sibbald et al., "Randomised controlled trial of non-directive counselling, cognitive-behaviour therapy, and usual general practitioner care for patients with depression. II: cost effectiveness," British Medical Journal, vol. 321, no. 7273, pp. 1389-1392, 2000.

[15] M. King, B. Sibbald, E. Ward et al., "Randomised controlled trial of non-directive counselling, cognitive-behaviour therapy and usual general practitioner care in the management of depression as well as mixed anxiety and depression in primary care," Health Technology Assessment, vol. 4, no. 19, pp. 1-73, 2000.

[16] M. A. Serfaty, D. Haworth, M. Blanchard, M. Buszewicz, S. Murad, and M. King, "Clinical effectiveness of individual cognitive behavioral therapy for depressed older people in primary care: a randomized controlled trial," Archives of General Psychiatry, vol. 66, no. 12, pp. 1332-1340, 2009.

[17] D. Kessler, G. Lewis, S. Kaur et al., "Therapist-delivered internet psychotherapy for depression in primary care: a randomised controlled trial," The Lancet, vol. 374, no. 9690, pp. 628-634, 2009.

[18] G. E. Simon, E. J. Ludman, and C. M. Rutter, "Incremental benefit and cost of telephone care management and telephone psychotherapy for depression in primary care," Archives of General Psychiatry, vol. 66, no. 10, pp. 1081-1089, 2009.

[19] Internet World Stats: Usage and Population Statistics, 2009, http://www.internetworldstats.com/stats.htm.

[20] Pew Internet and American Life Project, 2005, http://www .flickr.com/photos/cambodia4kidsorg/755159352/.

[21] Harris Poll, Almost three-quarters of all U.S. adults-an estimated 163 million, Harris Interactive, 2005, http://www .harrisinteractive.com/Insights/HarrisVault.aspx?PID=569.

[22] D. Weir, One in twenty Americans use Twitter, 2009.

[23] Anonymous, Older adults using Internet more, traditional media less. MarketingVOX: the voice of online marketing, 2006, http://www.marketingvox.com/older_adults_using_internet_more_traditional_media_less-020721/.

[24] A. Beattie, A. Shaw, S. Kaur, and D. Kessler, "Primary-care patients' expectations and experiences of online cognitive behavioural therapy for depression: a qualitative study," Health Expectations, vol. 12, no. 1, pp. 45-59, 2009.

[25] D. Kessler, G. Lewis, S. Kaur et al., "Therapist-delivered internet psychotherapy for depression in primary care: a randomised controlled trial," The Lancet, vol. 374, no. 9690, pp. 628-634, 2009.

[26] J. W. Pennebaker and J. D. Seagal, "Forming a story: the health benefits of narrative," Journal of Clinical Psychology, vol. 55, pp. 1243-1254, 1999.

[27] P. G. Frisina, J. C. Borod, and S. J. Lepore, "A meta-analysis of the effects of written emotional disclosure on the health outcomes of clinical populations," Journal of Nervous and Mental Disease, vol. 192, no. 9, pp. 629-634, 2004.

[28] Y. Y. Chen, "Written emotional expression and religion: effects on PTSD symptoms," International Journal of Psychiatry in Medicine, vol. 35, no. 3, pp. 273-286, 2005.

[29] P. R. Bennett, Prayers about traumatic experiences as selfdisclosure to God: implications for health and well-being [Ph.D. dissertation], University of Nevada, Reno, Nev, USA, 2006.

[30] H. Christensen, K. M. Griffiths, A. J. Mackinnon, and K. Brittliffe, "Online randomized controlled trial of brief and 
full cognitive behaviour therapy for depression," Psychological Medicine, vol. 36, no. 12, pp. 1737-1746, 2006.

[31] G. Andersson and P. Cuijpers, "Pros and cons of online cognitive-behavioural therapy," British Journal of Psychiatry, vol. 193, no. 4, pp. 270-271, 2008.

[32] G. E. Simon, E. J. Ludman, S. Tutty, B. Operskalski, and M. Von Korff, "Telephone psychotherapy and telephone care management for primary care patients starting antidepressant treatment: a randomized controlled trial," JAMA, vol. 292, no. 8, pp. 935-942, 2004.

[33] G. E. Simon, E. J. Ludman, and C. M. Rutter, "Incremental benefit and cost of telephone care management and telephone psychotherapy for depression in primary care," Archives of General Psychiatry, vol. 66, no. 10, pp. 1081-1089, 2009.

[34] H. G. Koenig, "History of mental health care," in Faith \& Mental Health, H. G. Koenig, Ed., pp. 17-39, Templeton Foundation Press, Philadelphia, PA, USA, 2005.

[35] A. J. Weaver, "Has there been a failure to prepare and support parish-based clergy in their role as frontline community mental health workers: a review," Journal of Pastoral Care, vol. 49, no. 2, pp. 129-147, 1995.

[36] S. Freud, "Future of an illusion," in Standard Edition of the Complete Psychological Works of Sigmund Freud, J. Strachey, Ed., p. 43, Hogarth Press, London, UK, 1962.

[37] H. G. Koenig, "Religion and mental health: what are psychiatrists doing and should do?" Psychiatric Bulletin, vol. 32, no. 6, pp. 201-203, 2008.

[38] S. Dein, C. C. H. Cook, A. Powell, and S. Eagger, "Religion, spirituality and mental health," Psychiatrist, vol. 34, no. 2, pp. 63-64, 2010.

[39] D. B. Larson, S. B. Thielman, M. A. Greenwold et al., "Religious content in the DSM-III-R Glossary of Technical Terms," American Journal of Psychiatry, vol. 150, no. 12, pp. 1884-1885, 1993.

[40] W. Watters, Deadly Doctrine: Health, Illness, and Christian God-Talk, Prometheus Books, Buffalo, NY, USA, 1992.

[41] H. E. Jones, Religion: The Etiology of Mental Illness, Mental Health Education Press, 2007.

[42] F. A. Curlin, R. E. Lawrence, S. Odell et al., "Religion, spirituality, and medicine: psychiatrists' and other physicians' differing observations, interpretations, and clinical approaches," American Journal of Psychiatry, vol. 164, no. 12, pp. 1825-1831, 2007.

[43] Pew Forum, U.S. religious landscape survey, 2007, http:// religions.pewforum.org/.

[44] The Gallup Poll, State of the States: Importance of Religion, http://www.gallup.com/poll/114022/state-states-importancereligion.aspx.

[45] H. G. Koenig, D. B. Larson, and S. S. Larson, "Religion and coping with serious medical illness," Annals of Pharmacotherapy, vol. 35, no. 3, pp. 352-359, 2001.

[46] H. G. Koenig, D. E. King, and V. B. Carson, Handbook of Religion and Health, Oxford University Press, New York, NY, USA, 2011.

[47] K. Pargament, The Psychology of Religion and Coping, Guilford Press, New York, NY, USA, 1997.

[48] H. G. Koenig, "Religious beliefs and practices of hospitalized medically ill older adults," International Journal of Geriatric Psychiatry, vol. 13, pp. 213-224, 1998.

[49] P. Pressman, J. S. Lyons, D. B. Larson, and J. J. Strain, "Religious belief, depression, and ambulation status in elderly women with broken hips," American Journal of Psychiatry, vol. 147, no. 6, pp. 758-760, 1990.
[50] H. G. Koenig, H. J. Cohen, D. G. Blazer et al., "Religious coping and depression among elderly, hospitalized medically ill men," American Journal of Psychiatry, vol. 149, no. 12, pp. 1693-1700, 1992.

[51] H. G. Koenig, "Religion and remission of depression in medical inpatients with heart failure/pulmonary disease," Journal of Nervous and Mental Disease, vol. 195, no. 5, pp. 389-395, 2007.

[52] H. G. Koenig, L. K. George, and B. L. Peterson, "Religiosity and remission of depression in medically ill oder patients," American Journal of Psychiatry, vol. 155, no. 4, pp. 536-542, 1998.

[53] H. G. Koenig, D. E. King, and V. B. Carson, Handbook of Religion and Health, Oxford University Press, New York, NY, USA, 2nd edition, 2012.

[54] M. E. McCullough, R. A. Emmons, and J. A. Tsang, "The grateful disposition: a conceptual and empirical topography," Journal of Personality and Social Psychology, vol. 82, no. 1, pp. 112-127, 2002.

[55] R. A. Emmons and T. T. Kneezel, "Giving thanks: spiritual and religious correlates of gratitude," Journal of Psychology and Christianity, vol. 24, no. 2, pp. 140-148, 2005.

[56] A. F. Shariff and A. Norenzayan, "God is watching you: priming God concepts increases prosocial behavior in an anonymous economic game," Psychological Science, vol. 18, no. 9, pp. 803-809, 2007.

[57] N. Krause, "Religious involvement, gratitude, and change in depressive symptoms over time," International Journal for the Psychology of Religion, vol. 19, no. 3, pp. 155-172, 2009.

[58] H. G. Koenig, "Religion and depression in older medical inpatients," American Journal of Geriatric Psychiatry, vol. 15, no. 4, pp. 282-291, 2007.

[59] D. L. Evans, T. R. Ten Have, S. D. Douglas et al., "Association of depression with viral load, CD8 T lymphocytes, and natural killer cells in women with HIV infection," American Journal of Psychiatry, vol. 159, no. 10, pp. 1752-1759, 2002.

[60] A. J. Zautra, D. C. Yocum, I. Villanueva et al., "Immune activation and depression in women with rheumatoid arthritis," Journal of Rheumatology, vol. 31, no. 3, pp. 457-463, 2004.

[61] P. H. Thaker, S. K. Lutgendorf, and A. K. Sood, "The neuroendocrine impact of chronic stress on cancer," Cell Cycle, vol. 6, no. 4, pp. 430-433, 2007.

[62] S. K. Lutgendorf, D. M. Lamkin, K. DeGeest et al., "Depressed and anxious mood and T-cell cytokine expressing populations in ovarian cancer patients," Brain, Behavior, and Immunity, vol. 22, no. 6, pp. 890-900, 2008.

[63] S. K. Lutgendorf, K. DeGeest, C. Y. Sung et al., "Depression, social support, and beta-adrenergic transcription control in human ovarian cancer," Brain, Behavior, and Immunity, vol. 23, no. 2, pp. 176-183, 2009.

[64] M. R. Irwin and A. H. Miller, "Depressive disorders and immunity: 20 years of progress and discovery," Brain, Behavior, and Immunity, vol. 21, no. 4, pp. 374-383, 2007.

[65] B. E. Leonard and A. Myint, "The psychoneuroimmunology of depression," Human Psychopharmacology, vol. 24, no. 3, pp. 165-175, 2009.

[66] M. A. Rosenkranz, D. C. Jackson, K. M. Dalton et al., "Affective style and in vivo immune response: neurobehavioral mechanisms," Proceedings of the National Academy of Sciences of the United States of America, vol. 100, no. 19, pp. 1114811152, 2003.

[67] A. H. Miller, "Neuroendocrine and immune system interactions in stress and depression," Psychiatric Clinics of North America, vol. 21, no. 2, pp. 443-463, 1998. 
[68] J. K. Kiecolt-Glaser, K. J. Preacher, R. C. MacCallum, C. Atkinson, W. B. Malarkey, and R. Glaser, "Chronic stress and age-related increases in the proinflammatory cytokine IL-6," Proceedings of the National Academy of Sciences of the United States of America, vol. 100, no. 15, pp. 9090-9095, 2003.

[69] M. B. Howren, D. M. Lamkin, and J. Suls, "Associations of depression with c-reactive protein, IL-1, and IL-6: a metaanalysis," Psychosomatic Medicine, vol. 71, no. 2, pp. 171-186, 2009.

[70] K. A. Hestad, S. Tonseth, C. D. Stoen, T. Ueland, and P. Aukrust, "Raised plasma levels of tumor necrosis factor alpha in patients with depression: normalization during electroconvulsive therapy," Journal of Electroconvulsive Therapy, vol. 19, pp. 183-188, 2003.

[71] C. Tuglu, S. H. Kara, O. Caliyurt, E. Vardar, and E. Abay, "Increased serum tumor necrosis factor-alpha levels and treatment response in major depressive disorder," Psychopharmacology, vol. 170, no. 4, pp. 429-433, 2003.

[72] B. E. Leonard and A. Myint, "The psychoneuroimmunology of depression," Human Psychopharmacology, vol. 24, no. 3, pp. 165-175, 2009.

[73] S. J. Schleifer, S. E. Keller, and A. T. Meyerson, "Lymphocyte function in major depressive disorder," Archives of General Psychiatry, vol. 41, no. 5, pp. 484-486, 1984.

[74] S. J. Schleifer, S. E. Keller, R. N. Bond, J. Cohen, and M. Stein, "Major depressive disorder and immunity. Role of age, sex, severity, and hospitalization," Archives of General Psychiatry, vol. 46, no. 1, pp. 81-87, 1989.

[75] M. Irwin, T. L. Smith, and J. C. Gillin, "Electroencephalographic sleep and natural killer activity in depressed patients and control subjects," Psychosomatic Medicine, vol. 54, no. 1, pp. 10-21, 1992.

[76] R. W. Bartrop, E. Luckhurst, and L. Lazarus, "Depressed lymphocyte function after bereavement," The Lancet, vol. 1, no. 8016, pp. 834-836, 1977.

[77] E. P. Zorrilla, L. Luborsky, J. R. McKay et al., "The relationship of depression and stressors to immunological assays: a meta-analytic review," Brain, Behavior, and Immunity, vol. 15, no. 3, pp. 199-226, 2001.

[78] K. A. Hestad, S. Tonseth, C. D. Stoen, T. Ueland, and P. Aukrust, "Raised plasma levels of tumor necrosis factor alpha in patients with depression: normalization during electroconvulsive therapy," Journal of Electroconvulsive Therapy, vol. 19, pp. 183-188, 2003.

[79] C. Tuglu, S. H. Kara, O. Caliyurt, E. Vardar, and E. Abay, "Increased serum tumor necrosis factor-alpha levels and treatment response in major depressive disorder," Psychopharmacology, vol. 170, no. 4, pp. 429-433, 2003.

[80] N. Castanon, B. E. Leonard, P. J. Neveu, and R. Yirmiya, "Effects of antidepressants on cytokine production and actions," Brain, Behavior, and Immunity, vol. 16, no. 5, pp. 569-574, 2002.

[81] M. H. Antoni, D. G. Cruess, N. Klimas et al., "Increases in a marker of immune system reconstitution are predated by decreases in 24-h urinary cortisol output and depressed mood during a 10-week stress management intervention in symptomatic HIV-infected men," Journal of Psychosomatic Research, vol. 58, no. 1, pp. 3-13, 2005.

[82] M. H. Antoni, S. Lechner, A. Diaz et al., "Cognitive behavioral stress management effects on psychosocial and physiological adaptation in women undergoing treatment for breast cancer," Brain, Behavior, and Immunity, vol. 23, no. 5, pp. 580-591, 2009.
[83] H. Van Middendorp, R. Geenen, M. J. Sorbi, L. J. P. Van Doornen, and J. W. J. Bijlsma, "Health and physiological effects of an emotional disclosure intervention adapted for application at home: a randomized clinical trial in rheumatoid arthritis," Psychotherapy and Psychosomatics, vol. 78, no. 3, pp. 145-151, 2009.

[84] L. S. Berk, S. Tan, and L. G. Tan, "Mirthful laughter, as adjunct therapy in diabetic care, increases HDL cholesterol and attenuates inflammatory cytokines and CRP and possible CVD risk," The FASEB Journal, 2009, Abstract no. 370.

[85] A. D. L. Roberts, A. S. Papadopoulos, S. Wessely, T. Chalder, and A. J. Cleare, "Salivary cortisol output before and after cognitive behavioural therapy for chronic fatigue syndrome," Journal of Affective Disorders, vol. 115, no. 1-2, pp. 280-286, 2009.

[86] L. H. Powell, L. Shahabi, and C. E. Thoresen, "Religion and spirituality. Linkages to physical health," American Psychologist, vol. 58, no. 1, pp. 36-52, 2003.

[87] Y. Chida, A. Steptoe, and L. H. Powell, "Religiosity/spirituality and mortality: a systematic quantitative review," Psychotherapy and Psychosomatics, vol. 78, no. 2, pp. 81-90, 2009.

[88] K. S. Seybold and P. C. Hill, "The role of religion and spirituality in mental and physical health," Current Directions in Psychological Science, vol. 10, no. 1, pp. 21-24, 2001.

[89] H. G. Koenig and H. J. Cohen, The Link Between Religion and Health: Psychoneuroimmunology and the Faith Factor, Oxford University Press, New York, NY, USA, 2002.

[90] J. Levin, "How faith heals: a theoretical model," Explore, vol. 5, no. 2, pp. 77-96, 2009.

[91] S. E. Sephton, C. Koopman, M. Schaal, C. Thoresen, and D. Spiegel, "Spiritual expression and immune status in women with metastatic breast cancer: an exploratory study," Breast Journal, vol. 7, no. 5, pp. 345-353, 2001.

[92] G. Ironson, R. Stuetzle, and M. A. Fletcher, "An increase in religiousness/spirituality occurs after HIV diagnosis and predicts slower disease progression over 4 years in people with HIV," Journal of General Internal Medicine, vol. 21, no. 5, pp. S62-S68, 2006.

[93] T. E. Woods, M. H. Antoni, G. H. Ironson, and D. W. Kling, "Religiosity is associated with affective and immune status in symptomatic HIV-infected gay men," Journal of Psychosomatic Research, vol. 46, no. 2, pp. 165-176, 1999.

[94] N. L. McCain, D. P. Gray, R. K. Elswick et al., "A randomized clinical trial of alternative stress management interventions in persons with HIV infection," Journal of Consulting and Clinical Psychology, vol. 76, no. 3, pp. 431-441, 2008.

[95] P. Lissoni, G. Messina, D. Parolini et al., "A spiritual approach in the treatment of cancer: relation between faith score and response to chemotherapy in advanced non-small cell lung cancer patients," In Vivo, vol. 22, no. 5, pp. 577-582, 2008.

[96] H. G. Koenig, H. J. Cohen, L. K. George, J. C. Hays, D. B. Larson, and D. G. Blazer, "Attendance at religious services, interleukin-6, and other biological parameters of immune function in older adults," International Journal of Psychiatry in Medicine, vol. 27, no. 3, pp. 233-250, 1997.

[97] S. K. Lutgendorf, P. Ullrich, R. Wallace, D. Russell, and T. B. Harris, "Religious participation, interleukin-6, and mortality in older adults," Health Psychology, vol. 23, no. 5, pp. 465475, 2004.

[98] D. E. King, A. G. Mainous, and W. S. Pearson, "C-reactive protein, diabetes, and attendance at religious services," Diabetes Care, vol. 25, no. 7, pp. 1172-1176, 2002. 
[99] E. A. Dedert, J. L. Studts, I. Weissbecker, P. G. Salmon, P. L. Banis, and S. E. Sephton, "Private religious practice: protection of cortisol rhythms among women with fibromyalgia," International Journal of Psychiatry in Medicine, vol. 34, pp. 61-77, 2004

[100] J. Tartaro, L. J. Luecken, and H. E. Gunn, "Exploring heart and soul: effects of religiosity/spirituality and gender on blood pressure and cortisol stress responses," Journal of Health Psychology, vol. 10, no. 6, pp. 753-766, 2005.

[101] G. Ironson, G. F. Solomon, E. G. Balbin et al., "The IronsonWoods Spirituality/Religiousness Index is associated with long survival, health behaviors, less distress, and low cortisol in people with HIV/AIDS," Annals of Behavioral Medicine, vol. 24, no. 1, pp. 34-48, 2002.

[102] A. W. Carrico, G. Ironson, M. H. Antoni et al., "A path model of the effects of spirituality on depressive symptoms and 24h urinary-free cortisol in HIV-positive persons," Journal of Psychosomatic Research, vol. 61, no. 1, pp. 51-58, 2006.

[103] C. L. W. Chan, R. T. H. Ho, P. W. H. Lee et al., "A randomized controlled trial of psychosocial interventions using the psychophysiological framework for Chinese breast cancer patients," Journal of Psychosocial Oncology, vol. 24, no. 1, pp. 3-26, 2006.

[104] N. L. McCain, D. P. Gray, R. K. Elswick et al., "A randomized clinical trial of alternative stress management interventions in persons with HIV infection," Journal of Consulting and Clinical Psychology, vol. 76, no. 3, pp. 431-441, 2008.

[105] R. J. Davidson, J. Kabat-Zinn, J. Schumacher et al., "Alterations in brain and immune function produced by mindfulness meditation," Psychosomatic Medicine, vol. 65, no. 4, pp. 564-570, 2003.

[106] T. W. W. Pace, L. T. Negi, D. D. Adame et al., "Effect of compassion meditation on neuroendocrine, innate immune and behavioral responses to psychosocial stress," Psychoneuroendocrinology, vol. 34, no. 1, pp. 87-98, 2009.

[107] L. Witek-Janusek, K. Albuquerque, K. R. Chroniak, C. Chroniak, R. Durazo-Arvizu, and H. L. Mathews, "Effect of mindfulness based stress reduction on immune function, quality of life and coping in women newly diagnosed with early stage breast cancer," Brain, Behavior, and Immunity, vol. 22, no. 6, pp. 969-981, 2008.

[108] R. Sudsuang, V. Chentanez, and K. Veluvan, "Effect of Buddhist meditation on serum cortisol and total protein levels, blood pressure, pulse rate, lung volume and reaction time," Physiology and Behavior, vol. 50, no. 3, pp. 543-548, 1991.

[109] J. R. Infante, F. Peran, M. Martinez et al., "ACTH and betaendorphin in transcendental medication," Physiology \& Behavior, vol. 64, pp. 311-315, 1998.

[110] K. G. Walton, J. Z. Fields, D. K. Levitsky, D. A. Harris, N. D. Pugh, and R. H. Schneider, "Lowering cortisol and CVD risk in postmenopausal women: a pilot study using the transcendental meditation program," Annals of the New York Academy of Sciences, vol. 1032, pp. 211-215, 2004.

[111] P. Jin, "Efficacy of Tai Chi, brisk walking, meditation, and reading in reducing mental and emotional stress," Journal of Psychosomatic Research, vol. 36, no. 4, pp. 361-370, 1992.

[112] J. A. Curiati, E. Bocchi, J. O. Freire et al., "Meditation reduces sympathetic activation and improves the quality of life in elderly patients with optimally treated heart failure: a prospective randomized study," Journal of Alternative and Complementary Medicine, vol. 11, no. 3, pp. 465-472, 2005.

[113] J. Granath, S. Ingvarsson, U. von Thiele, and U. Lundberg, "Stress management: a randomized study of cognitive behavioural therapy and yoga," Cognitive Behaviour Therapy, vol. 35, no. 1, pp. 3-10, 2006.

[114] H. G. Koenig, Medicine, Religion and Health, Templeton Foundation Press, Philadelphia, Pa, USA, 2008.

[115] L. R. Propst, R. Ostrom, P. Watkins, T. Dean, and D. Mashburn, "Comparative efficacy of religious and nonreligious cognitive-behavioral therapy for the treatment of clinical depression in religious individuals," Journal of Consulting and Clinical Psychology, vol. 60, no. 1, pp. 94-103, 1992.

[116] R. Bowen, M. Baetz, C. D'Arcy, and R. Bowen, "Self-rated importance of religion predicts one-year outcome of patients with panic disorder," Depression and Anxiety, vol. 23, no. 5, pp. 266-273, 2006.

[117] L. R. Propst, "The comparative efficacy of religious and nonreligious imagery for the treatment of mild depression in religious individuals," Cognitive Therapy and Research, vol. 4, no. 2, pp. 167-178, 1980.

[118] L. R. Propst, R. Ostrom, P. Watkins, T. Dean, and D. Mashburn, "Comparative efficacy of religious and nonreligious cognitive-behavioral therapy for the treatment of clinical depression in religious individuals," Journal of Consulting and Clinical Psychology, vol. 60, no. 1, pp. 94-103, 1992.

[119] D. H. Rosmarin, K. I. Pargament, S. Pirutinsky, and A. Mahoney, "A randomized controlled evaluation of a spiritually integrated treatment for subclinical anxiety in the Jewish community, delivered via the Internet," Journal of Anxiety Disorders, vol. 24, no. 7, pp. 799-808, 2010.

[120] M. Z. Azhar, S. L. Varma, and A. S. Dharap, "Religious psychotherapy in anxiety disorder patients," Acta Psychiatrica Scandinavica, vol. 90, no. 1, pp. 1-3, 1994.

[121] M. Z. Azhar and S. L. Varma, "Religious psychotherapy in depressive patients," Psychotherapy and Psychosomatics, vol. 63, no. 3-4, pp. 165-168, 1995.

[122] M. Z. Azhar and S. L. Varma, "Religious psychotherapy as management of bereavement," Acta Psychiatrica Scandinavica, vol. 91, no. 4, pp. 233-235, 1995.

[123] S. M. Razali, C. I. Hasanah, K. Aminah, and M. Subramaniam, "Religious-sociocultural psychotherapy in patients with anxiety and depression," Australian and New Zealand Journal of Psychiatry, vol. 32, no. 6, pp. 867-872, 1998.

[124] S. Xiao, D. Young, and H. Zhang, "Taoistic cognitive psychotherapy for neurotic patients: a preliminary clinical trial," Psychiatry and Clinical Neurosciences, vol. 52, supplement, pp. S238-S241, 1998.

[125] M. A. Stanley, A. L. Bush, M. E. Camp et al., "Older adults' preferences for religion/spirituality in treatment of anxiety and depression," Aging and Mental Health, vol. 15, no. 3, pp. 334-343, 2011.

[126] E. M. Rose, J. S. Westefeld, and T. N. Ansley, "Spiritual issues in counselling: clients' beliefs and preferences," Journal of Counseling Psychology, vol. 48, no. 1, pp. 61-71, 2001.

[127] E. W. Kelly Jr., "Spirituality and religion in counselor education: a national survey," Counselor Education and Supervision, vol. 33, pp. 227-237, 1995.

[128] N. Krause, "Religious involvement, gratitude, and change in depressive symptoms over time," International Journal for the Psychology of Religion, vol. 19, no. 3, pp. 155-172, 2009.

[129] K. M. Sheldon, "How to increase and sustain positive emotion: the effects of expressing gratitude and visualizing vest possible selves," Journal of Positive Psychology, vol. 1, pp. 73-82, 2006.

[130] S. J. Morris and F. H. Kanfer, "Altruism and depression," Personality and Social Psychology Bulletin, vol. 9, pp. 567-577, 1983. 
[131] T. Fujiwara, "The role of altruistic behavior in generalized anxiety disorder and major depression among adults in the United States," Journal of Affective Disorders, vol. 101, no. 13, pp. 219-225, 2007.

[132] H. G. Koenig, D. E. King, and V. B. Carson, Handbook of Religion and Health, Oxford University Press, New York, NY, USA, 2nd edition, 2012.

[133] B. C. Post and N. G. Wade, "Religion and spirituality in psychotherapy: a practice-friendly review of research," Journal of Clinical Psychology, vol. 65, no. 2, pp. 131-146, 2009.

[134] B. J. Rounsaville, K. M. Carroll, and L. S. Onken, "A stage model of behavioral therapies research: getting started and moving on from stage I," Clinical Psychology, vol. 8, no. 2, pp. 133-142, 2001.

[135] K. Pargament, Spiritually Integrated Psychotherapy: Understanding and Addressing the Sacred, Guilford Press, New York, NY, USA, 2007.

[136] L. R. Propst, R. Ostrom, P. Watkins, T. Dean, and D. Mashburn, "Comparative efficacy of religious and nonreligious cognitive-behavioral therapy for the treatment of clinical depression in religious individuals," Journal of Consulting and Clinical Psychology, vol. 60, no. 1, pp. 94-103, 1992.

[137] B. C. Post and N. G. Wade, "Religion and spirituality in psychotherapy: a practice-friendly review of research," Journal of Clinical Psychology, vol. 65, no. 2, pp. 131-146, 2009. 


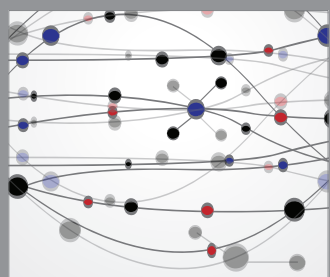

The Scientific World Journal
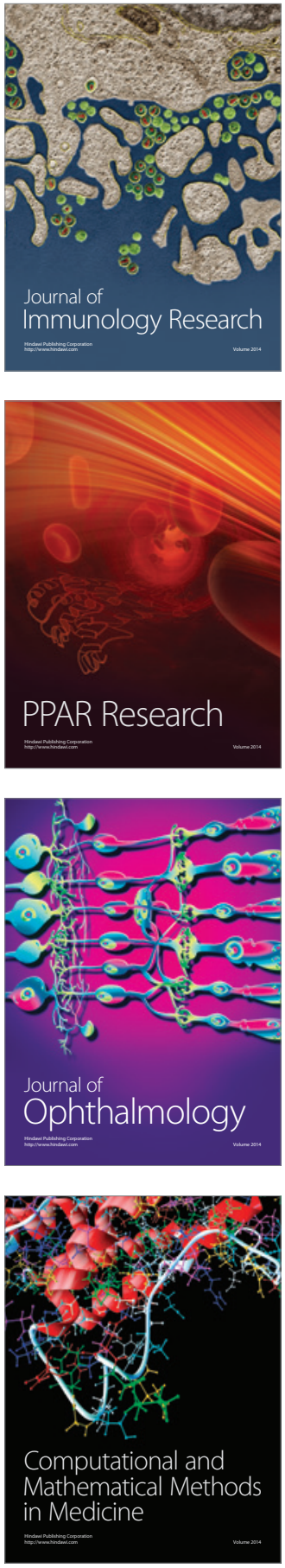

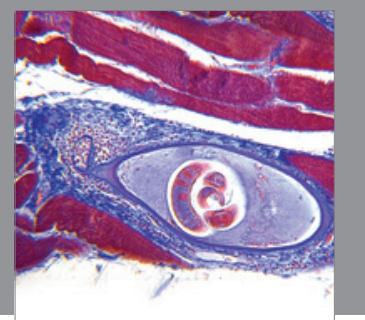

Gastroenterology

Research and Practice
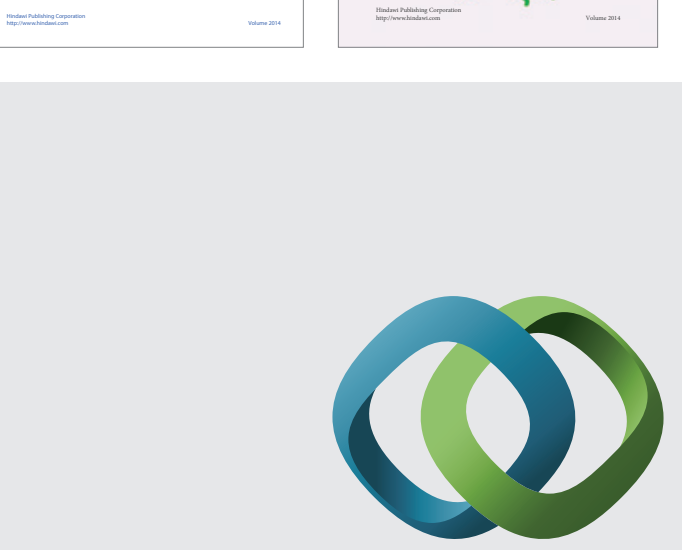

\section{Hindawi}

Submit your manuscripts at

http://www.hindawi.com
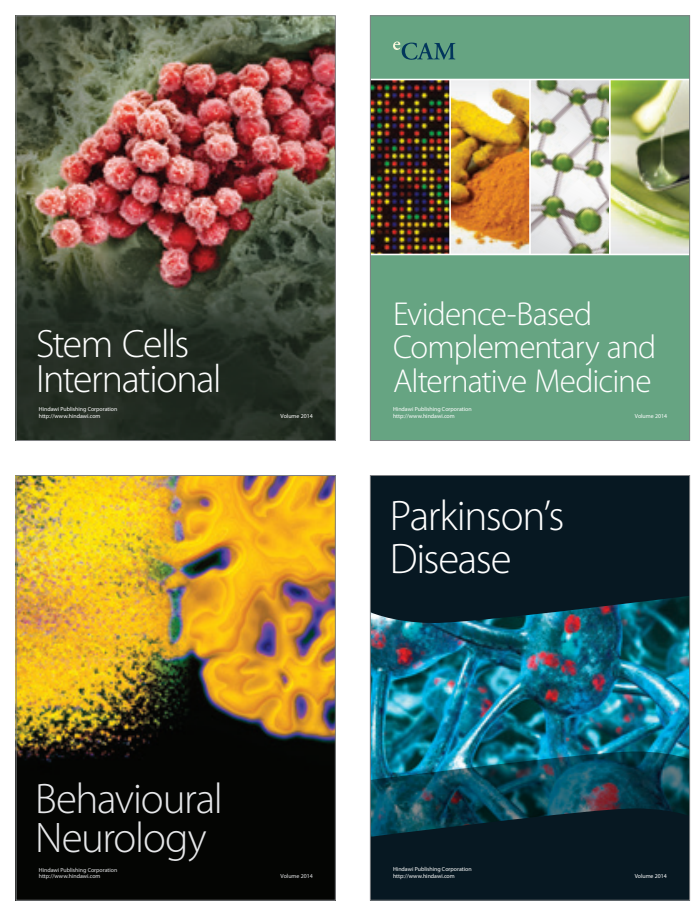

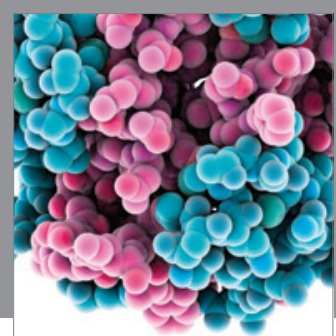

Journal of
Diabetes Research

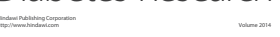

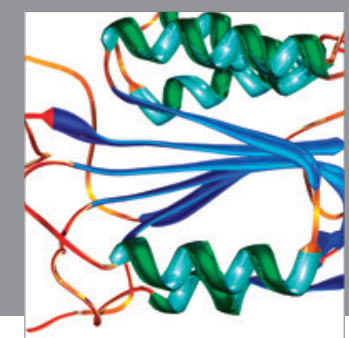

Disease Markers
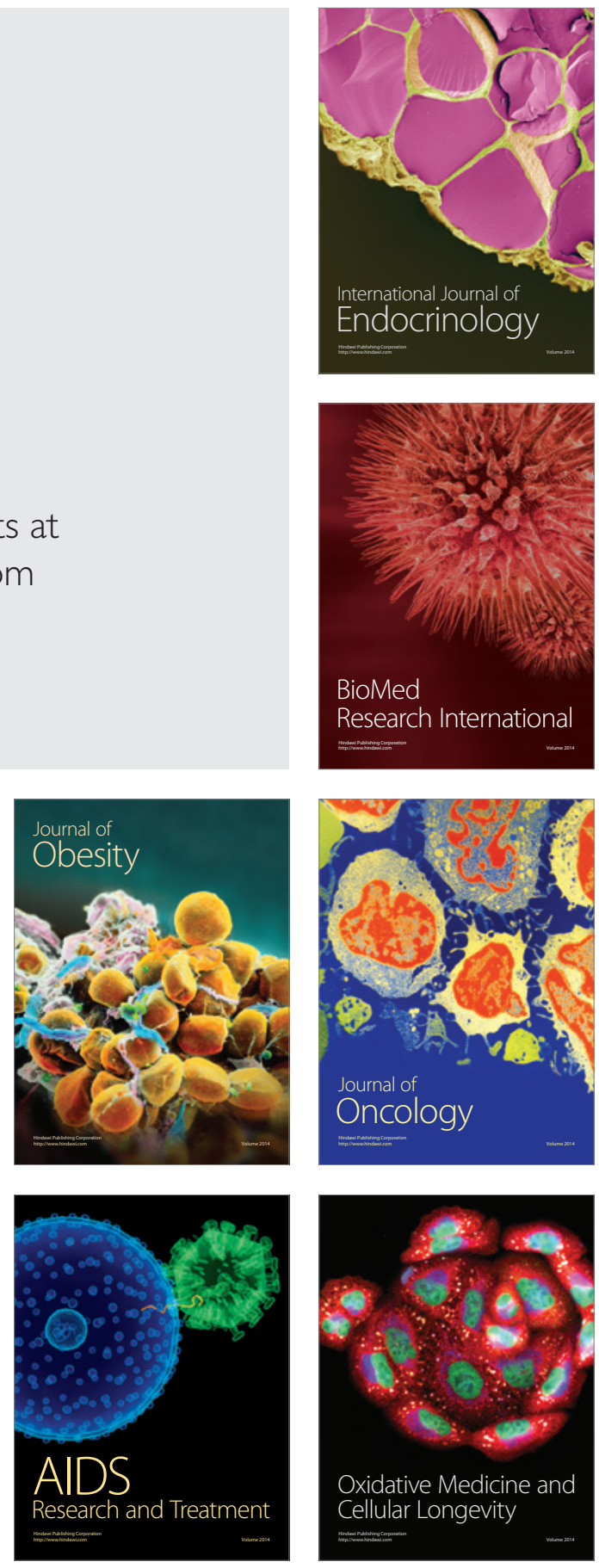